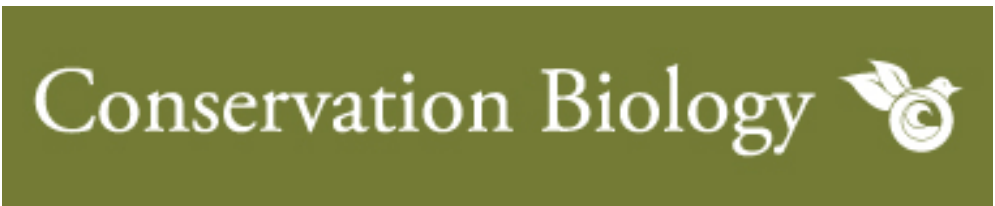

\title{
Effects of protected areas on survival of threatened gibbons in China
}

\begin{tabular}{|c|c|}
\hline Journal: & Conservation Biology \\
\hline Manuscript ID & 20-492.R1 \\
\hline Wiley - Manuscript type: & Contributed Paper \\
\hline Keywords: & $\begin{array}{l}\text { brake effect, gibbon, habitat, nature reserve, population trends, } \\
\text { protected area management effectiveness }\end{array}$ \\
\hline Abstract: & $\begin{array}{l}\text { Establishing protected areas (PAs) is an essential strategy to reduce } \\
\text { biodiversity loss. However, many PAs do not provide adequate protection } \\
\text { due to poor funding, inadequate staffing and equipment, and ineffective } \\
\text { management. As part of China's recent economic growth, the Chinese } \\
\text { government has significantly increased investment in nature reserves } \\
\text { over the past } 20 \text { years, providing a unique opportunity to evaluate } \\
\text { whether PAs can protect threatened species effectively. We compiled } \\
\text { data on populations of gibbons (Hylobatidae; threatened flagship species } \\
\text { with cultural significance) that occurred in Chinese reserves post-1980, } \\
\text { and evaluated the ability of these PAs to maintain gibbon habitats and } \\
\text { populations. We also assessed the perspective of reserve staff } \\
\text { concerning PA management effectiveness. We found that reserves were } \\
\text { effective in protecting gibbon habitat by reducing forest loss and human } \\
\text { disturbance; however, half of the reserves lost their gibbon populations } \\
\text { since being established. Gibbons were more likely to survive in recently } \\
\text { established reserves, with higher elevation, less forest loss, less human } \\
\text { impact, and more scientific research. A larger initial population size in } \\
\text { the } 1980 \text { s was also positively associated with gibbon persistence. } \\
\text { Although all reserves reported increased investment and improved } \\
\text { management over the past } 20-30 \text { years, no relationship was found } \\
\text { between management scores and gibbon population trends. We suggest } \\
\text { early investment is critical. This is analogous to preventing a traffic } \\
\text { accident: conservation practitioners must brake population decline early, } \\
\text { and brake emphatically to prevent extinction. }\end{array}$ \\
\hline
\end{tabular}

\section{SCHOLARONE" Manuscripts}




\section{Effects of protected areas on survival of threatened gibbons in China}

2

3 Abstract: Establishing protected areas (PAs) is an essential strategy to reduce biodiversity loss. However, many PAs do not provide adequate protection due to poor funding, inadequate staffing and equipment, and ineffective management. As part of China's recent economic growth, the Chinese government has significantly increased investment in nature reserves over the past 20 years, providing a unique opportunity to evaluate whether PAs can protect threatened species effectively. We compiled data on populations of gibbons (Hylobatidae; threatened flagship species with cultural significance) that occurred in Chinese reserves post-1980, and evaluated the ability of these PAs to maintain gibbon habitats and populations. We also assessed the perspective of reserve staff concerning PA management effectiveness. We found that reserves were effective in protecting gibbon habitat by reducing forest loss and human disturbance; however, half of the reserves lost their gibbon populations since being established. Gibbons were more likely to survive in recently established reserves, with higher elevation, less forest loss, less human impact, and more scientific research. A larger initial population size in the 1980s was also positively associated with gibbon persistence. Although all reserves reported increased investment and improved management over the past 20-30 years, no relationship was found between management scores and gibbon population trends. We suggest early investment is critical. This is analogous to preventing a traffic accident: conservation practitioners must brake population decline early, and brake emphatically to prevent extinction. Keywords: brake effect, gibbon, habitat, nature reserve, population trends, protected area management effectiveness 


\section{Introduction}

Many actions have been taken to reduce biodiversity loss, among which the establishment of protected areas (PAs) is a fundamental global strategy (Margules \& Pressey 2000; Jenkins \& Joppa 2009). PAs can be effective in both reducing habitat loss and stopping declines of threatened wildlife populations (Geldmann et al. 2013). However, many PAs have not functioned as expected due to various reasons, including lack of funding, staffing, equipment and training, and ineffective management (Laurance et al. 2012; Watson et al. 2014). The most extreme examples are "paper parks", which are PAs with little or no formal management that do not provide adequate protection for biodiversity and exist only at the legislative level (Curran et al. 2004). Therefore, in addition to increasing the number and area of PAs, promoting their effectiveness is imperative to the success of biodiversity conservation. China is a huge country with a diverse range of habitats that support exceptionally rich biodiversity, including over 6000 vertebrate species (Xu et al. 1999). However, it also has the world's largest human population, and faces a serious biodiversity crisis following decades of rapid economic growth (Ouyang et al. 2016; Liu et al. 2018). To reduce biodiversity loss, China has established many nature reserves (the most common type of PAs in China); as of 2017, 2,750 nature reserves had been established (Xu et al. 2019). Together with other types of PAs, they cover $20 \%$ of China's terrestrial area (Ouyang et al. 2018), approximately equivalent to the area of Peru or 3 times the area of Spain or California. China has also increased financial investment into its reserves, reaching 5.50 USD/ha in 2009 (Li et al. 2013). However, the effectiveness of China's reserves in conserving biodiversity has rarely been evaluated (Quan et al. 2011; Ren et al. 2015). Among the few species in China for which the effectiveness of conservation actions 
51 have been evaluated is the iconic giant panda (Ailuropoda melanoleuca) (Kang \& Li

2018). Giant pandas receive tremendous conservation investment (currently $\sim$ US $\$ 140$

million per year for in situ conservation), are of high public interest, and are

extremely well researched (Wei et al. 2012; Swaisgood et al. 2018; Li 2020).

However, even the "flagship" reserves for pandas have not protected panda habitat effectively (Liu et al. 2001; Li et al. 2017). Although recent assessment has shown that panda populations and habitats have benefited greatly from reserves (Wei et al. 2020), total panda population size and habitat area have not recovered to pre-1988 levels (Wei et al. 2018). This high-profile example raises concerns that conservation actions for species receiving less attention or investment might be even less effective. Gibbons (Hylobatidae) are small arboreal apes that require intact forest canopy habitat. They were once widely distributed across China, and were culturally significant animals in ancient China (Fan 2017; Turvey et al. 2018). Their distribution has contracted dramatically over the past 400 years due to habitat loss and hunting (Chatterjee et al. 2012; Turvey et al. 2015; Fan 2017). Populations of 6 gibbon species survived in fragmented forests in 3 southwestern Chinese provinces (Guangxi, Hainan and Yunnan) into the 1980s (Fan 2017). To protect these remnant gibbon populations and their habitats, the Chinese government established a series of reserves, and $>80 \%$ of gibbon populations are found within protected areas (Fan 2017). Since 1989 all gibbons have been listed as Class I protected animals in China. Nonetheless, some populations continued to decline, and two species were recently extirpated in China (Grueter et al. 2009; Fan et al. 2014). It is therefore essential to evaluate the effectiveness of reserves for gibbon conservation in China, and to assess why different conservation efforts have had such varying levels of success.

$$
\text { We compiled data on changes in site-specific population size for all } 6 \text { gibbon }
$$


species that occurred post-1980 in China, and assessed the effectiveness of reserves on preserving gibbon habitats and populations. We then surveyed staff across reserves with extirpated or extant gibbon populations, to evaluate if perceived effectiveness of management explained variation in gibbon population trends. Using gibbons in China as an example, we aim to evaluate if PAs have been able to reverse population declines and halt biodiversity loss.

\section{Methods}

We compiled data on the distribution and status of all known recently extant (post1980) gibbon populations in China, and on the location, age, and administration level (national, provincial, and county-level) of all Chinese reserves where gibbons survive today or have recently occurred, from published literature and first-hand data collected by our group (Appendix S1). Some reserves consist of discrete management areas that were founded in different years or are managed by different agencies; these areas were considered separately. Reserve boundaries were downloaded from the World Database on Protected Areas (WDPA; https://protectedplanet.net/), and were modified when necessary after consulting reserve staff.

\section{Effects of reserves on gibbon habitat}

To test whether reserves have been effective at conserving gibbon habitat, we obtained forest data at $30 \mathrm{~m}$ resolution from Global Forest Change 2000-2018

\section{(https://earthenginepartners.appspot.com/science-2013-global-}

forest/download_v1.5.html), and compared overall forest cover within each reserve to the surrounding $5 \mathrm{~km}$ buffer zone in 2000, as well as percentage forest loss during 2000-2018 as per data availability. We also compared Human Footprint Index (NASA 
101 Socioeconomic Data and Applications Center,

102

103

104

105

106

107

108

109

110

111

112

113

114

115

116

117

118

119

120

121

122

123

124

125

https://sedac.ciesin.columbia.edu/data/set/wildareas-v3-1993-human-footprint), a comprehensive index of human pressure on environment at $1 \mathrm{~km}$ resolution, for both 1993 and 2009 between reserves and buffer zones. We used non-parametric MannWhitney U tests to conduct comparisons.

\section{Effects of characteristics of reserves on gibbon populations}

We used a logistic regression model to assess the impacts of reserve characteristics on presence/absence of gibbon populations after 2010 (dependent variable). Uncertain or unverified reports of local gibbon persistence (e.g., Turvey et al. 2017), were not accepted as evidence for continued gibbon survival. Reserves or specific management areas that were established after gibbons had been locally extirpated were excluded. We selected 12 variables based on previous studies that have shown a correlation with persistence of wildlife populations in PAs (Table 1). We calculated mean elevation and mean annual temperature of each reserve in ArcGIS version 10.3.1, based on $90 \mathrm{~m}$ resolution DEM data from SRTM v4 (http://srtm.csi.cgiar.org/SELECTION/inputCoord.asp) and 30 arc-seconds resolution temperature data from WorldClim (http://worldclim.org/version2). We also calculated mean topographic ruggedness index (TRI; Riley et al. 1999) derived from the DEM data. We collected publications about reserves and their gibbon populations by searching the China National Knowledge Infrastructure (CNKI; http://www.cnki.net/) and Web of Science (http://apps.webofknowledge.com). The size of gibbon populations in the 1980s was obtained from published literature (Appendix S2). All numerical independent variables were tested for collinearity prior to regression analysis. Elevation and temperature were found to be significantly correlated $(r=-$ 
$0.978, p<0.001)$, as were forest cover in 2000 and TRI $(r=-0.761, p<0.001)$. We retained elevation and forest cover in 2000 in the set of independent variables. As our sample size was small $(\mathrm{n}=18)$, we considered only one variable for each model and calculated their AICc value. Models with $\leq 2 \Delta \mathrm{AICc}$ were considered as having an equivalent support to the best model with the smallest AICc value (Burnham \& Anderson 2002). We then calculated Akaike weight $\left(\omega_{i}\right)$ for each model. Since no single model had an $\omega_{i}$ over 0.9 , we averaged top models that had a cumulative $\omega_{i}>0.9$ to obtain the coefficient and SE for each variable that was contained in top models. Relative importance of variables was determined based on $\omega_{i}$ of the top models, and variables with SE larger than the absolute value of coefficient were excluded from the final model. We used the area under the receiver operating characteristic curve (AUC) to determine performance of the final model, with 1.0 showing perfect discrimination ability and 0.5 showing no discrimination ability (Pearce \& Ferrier 2000).

\section{Effects of reserve management effectiveness on gibbon populations}

We conducted an online questionnaire survey on reserve management effectiveness (https://wj.qq.com/s2/4828422/a27a/). The questionnaire was based on the Management Effectiveness Tracking Tool, one of the most widely used systems to assess management effectiveness of PAs, and on the Technical Regulations for the Management Effectiveness Evaluation of Nature Reserves (LY/T 1726-2008) published by the State Forestry Administration of the People's Republic of China. We included 39 questions in 4 groupings (following Geldmann et al. 2017), including: ADesign and Planning (9 questions), B-Monitoring and Enforcement (11 questions), C-Capacity and Resources (9 questions), and D-Decision-making Arrangement (10 
151

152

153

154

155

156

157

158

questions). We contacted reserve staff and asked them to recall information from the 1980s, 1990s, 2000s, and 2010s, and then to fill out the questionnaire by self-scoring the performance of their reserves during each decade. Scores are integers and represent reserve performance from worst (0) to best (3); we provided a criterion for each score alongside the questions.

We aimed to find 3 participants from each reserve and recorded the year when they were employed. For each participant we summed the scores of all 39 questions, and the scores of questions included within each of the 4 groupings during each decade. We only included scores from participants for the decades during which they worked at their reserve. We calculated mean scores across all participants from the same area, and used these values as indices of management effectiveness. We used a Friedman rank sum test with a post-hoc Conover test to compare these scores across different decades to determine change in reserve management effectiveness over time. Since only 5 areas had staff who had worked there since the 1980 s, data from these 5 sites only were used to compare scores from the 1980s onwards. Data for more reserves or management areas were available from the 1990s onwards, so we conducted an additional comparison for this time series.

We then assessed the relationship between change of management effectiveness scores and gibbon population trends. Population trends were determined by comparing available estimates of gibbon populations between contiguous decades (based on data listed in Appendix S1), and classified as decreasing (estimates in the latter decade were smaller than those in the former decade, without range overlap), stable (estimates with range overlap), and increasing (estimates in the latter decade were larger and without range overlap). Since there were very few population trends classified as stable or increasing, we combined these two categories as non- 
decreasing. We then calculated change of management scores, as well as percentage change between those contiguous decades in which gibbon population trends were determined. We used a Mann-Whitney U test to compare mean scores for all questions and for questions in the 4 groupings between decreasing and non-decreasing events.

All analyses were conducted in R v3.5.0 (R Core Team 2016), using the packages ggplot2 (Wickham 2016), MuMIn (Bartoń 2016), usdm (Naimi et al. 2014), PMCMR (Pohlert 2014), raster (Hijmans 2020), and ROCR (Sing et al. 2005).

\section{Results}

\section{Change in gibbon survival and population size in reserves}

Gibbon populations recently occurred in areas covered today by 24 Chinese reserves or 32 distinct reserve management areas (Appendix S1). Huanglianshan used to contain both northern white-cheeked gibbon (Nomascus leucogenys) and western black crested gibbon ( $N$. concolor) but both species are now extirpated, and Nangunhe used to contain both lar gibbon (Hylobates lar) and N. concolor in separate areas but now only contains $\sim 2$ groups of $N$. concolor. Other reserves or management areas only have, or used to have, one gibbon species.

Most reserves or management areas (63\%) were established in the 1980s, with 7 established after gibbons had been locally extirpated in previous decades. The status of gibbon populations could not be determined at the time of establishment of 4 reserves or management areas. Gibbons disappeared in 10 areas after their establishment, and only 11 retained gibbons into the 2010 s.

Among the 32 management areas, 21 had been upgraded since their establishment, with 20 of them upgraded from provincial-level to national-level, and one from 
county-level to provincial-level (Appendix S1). Upgrades occurred 13.7 (SE 1.7, range: 3-28) years after reserves were founded, in the year 1999 (SE 2, range: 19862014). Among the 10 areas where gibbons disappeared after reserve establishment, 6 had been upgraded. However, gibbons disappeared in 4 areas before reserves were upgraded. Eight out of 11 areas where gibbons survived into the 2010s had been upgraded, and the percentage of reserves having been upgraded in this group was not different from that in the group of reserves where gibbons disappeared $\left(x^{2}=0.077 \mathrm{df}\right.$ $=1, p=0.782$ ).

\section{Effects of reserves on gibbon habitat}

Forest cover in 2000 was higher within reserves than in the buffer zones surrounding each reserve (72.3, SE 2.2 vs. 52.6, SE 2.6, $W=867, p<0.001$; Fig. 1a), and percentage forest loss was higher in buffer zones than within reserves $(2.63$, SE 0.78 vs. 8.11, SE 0.97, $W=128, p<0.001$; Fig. 1b). We found no difference in Human Footprint Index between reserves and buffer zones in 1993 (7.95, SE 0.36 vs. 8.48, SE $0.31, W=423, p=0.234$; Fig. 1c), but there was a significant difference in $2009(p<$ 0.001; Fig. 1d), with less human impact within reserves (7.74, SE 0.23) than in buffer zones (9.05, SE 0.26).

\section{Effects of reserve characteristics on gibbon populations}

Six of the 10 independent variables were retained in the final model, having significant impacts on gibbon survival into the 2010s (Table 2, 3). The AUC for the final model was 0.975 , indicating good discriminatory ability. In general, gibbons were more likely to survive in more recently established reserves, and in reserves 
located at higher elevations. Percentage forest loss and percentage Human Footprint Index change were negatively correlated with gibbon survival, and number of papers published was positively correlated with gibbon survival. Gibbon populations with a larger initial size in the 1980 s were also more likely to survive into the 2010s. Forest cover and reserve administration level (either current or at foundation), and whether reserve had been upgraded, were not correlated with gibbon survival.

\section{Effects of reserve management effectiveness on gibbon populations}

Sixty people from 21 reserves or management areas participated in our questionnaire survey. Excluding records without clear reserve or management area identification, we retained 49 records from 19 areas, with a mean of 2.6 participants per area (range: 1-6). Participants had worked in their reserves for a mean of 14.7 (SE 1.5) years. Management effectiveness scores increased over time (all $p \leq 0.003$ ), both from the 1980s (for 5 areas; Fig. 2a, Appendix S3) and from the 1990s (for 13 areas; Fig. 2b, Appendix S3). No changes of score or percentage changes between contiguous decades (either of all questions or of question groupings) were found to be different between decreasing $(n=8)$ and non-decreasing $(n=4)$ gibbon populations in corresponding decades (all $p>0.05$, Appendix S4). This result indicates there was no significant relationship between trends of gibbon populations and change/percentage change of management scores (of all questions or of question groupings).

\section{Discussion}

We evaluated the conservation effectiveness of Chinese PAs at protecting threatened gibbon populations and habitat. Over $80 \%$ of China's gibbons now live inside reserves (Fan 2017), but while we found that reserves were effective in protecting 
gibbon habitat through reducing forest loss and human impacts, they did not function well at protecting gibbon populations. Almost half of the reserves in China that formerly contained gibbons have lost these populations in the few decades since they were established, and gibbons have never recolonized a reserve in China once they became locally extirpated.

\section{Effectiveness of reserves for conserving gibbon habitat and populations}

Our analyses demonstrate that forest cover inside gibbon reserves is higher than in the surrounding buffer zones, and forest loss and human impacts are lower inside these reserves. This result indicates that reserves have been effective at protecting habitat compared to the status of their wider landscapes (cf. Geldmann et al. 2013). Some regional case studies have demonstrated that PAs are not always effective at maintaining habitat (Brower et al. 2002; Curran et al. 2004), and further steps are required to fulfill their conservation potential (Watson et al. 2014). However, many

PAs are effective in reducing forest loss and anthropogenic activities inside their boundaries, including other PAs in China (Wei et al. 2020).

However, whereas these reserves have generally protected gibbon habitat, they were not effective at protecting gibbon populations. Gibbons disappeared in almost half of the reserves or management areas since they were established. We identified several reserve characteristics that affected gibbon survival (Table 3). Initial population size of gibbons in the 1980s was positively associated with gibbon survival into the 2010s. This result is in accordance with the common pattern that small populations are more likely to become extinct due to inbreeding, genetic drift and demographic stochasticity, as well as increased vulnerability to hunting or other anthropogenic disturbance (e.g., Saccheri et al. 1998; Legendre et al. 1999). However, 
the Hainan gibbon ( $N$. hainanus) population at Bawangling is an exception to this general pattern. This population decreased to 7-9 known individuals in 1989 (Liu et al. 1989) and contained only 13 known individuals in 2003 (Zhou et al. 2005), but has now increased to more than 30 individuals (Chan et al. 2020). Nevertheless, the relative importance of initial population size was low (Table 3), suggesting that other variables have been more influential in determining gibbon survival in Chinese reserves.

Although forest loss in reserves was lower than in their surrounding buffer zones, loss still occurred inside reserves (see also Zhang et al. 2010), and percentage forest loss was inversely correlated with gibbon survival. Furthermore, our study assessed overall forest cover but not forest quality. Gibbons rely heavily on mature, undisturbed evergreen forest (Phoonjampa et al. 2011), and specific anthropogenic activities such as cardamom planting reduce the quality of gibbon habitat (Yuan et al. 2014). Such changes in habitat quality may explain why we found no correlation between forest cover and gibbon survival, and further investigation of both quantity and quality of gibbon habitat is needed.

We found that gibbons were more likely to survive in reserves at higher elevations (and with lower temperatures). This finding is consistent with longer-term patterns of local survival or extinction of gibbon populations across China during recent centuries (Chatterjee et al. 2012; Turvey et al. 2015). These patterns likely reflect the fact that lower-elevation landscapes typically have higher human populations and more associated anthropogenic pressures including poaching, agricultural encroachment, and livestock grazing (Fan \& Jiang 2010). Indeed, this likelihood is supported by our additional result that increased Human Footprint Index within reserves, a measure of the negative impacts associated with anthropogenic activities, was negatively 
associated with gibbon survival.

The number of papers published on gibbons and their reserves was positively correlated with gibbon presence. It is possible that researchers have conducted more studies in areas where gibbon populations are healthy and well managed.

Alternatively, scientific research has been demonstrated to help wildlife conservation through raising public awareness and concerns about threatened species, improving management of reserves through science-based decision-making, and attracting additional funding (Pusey et al. 2007; Hu et al. 2019). More importantly, gibbon studies, especially behavioral ones, usually require long-term fieldwork, and the presence of researchers and research sites in forests may be one of the most effective ways to prevent poaching (Piel et al. 2015; Chapman et al. 2017). We therefore encourage more long-term field studies, not only to improve our understanding of the conservation status and requirements of threatened populations, but also to support their practical protection.

We found that age of reserve was negatively associated with gibbon survival, contrary to our prediction that the earlier a landscape received protection, the greater the likelihood that populations would persist (Friedlander et al. 2017). This result clearly demonstrates that establishment of a reserve does not mean that its gibbons immediately received effective protection. Reserves founded several decades ago may not have received sufficient investment, and management effectiveness may have initially been low (Han 2000; Li et al. 2013). Our results also showed that human impacts within reserves did not differ from surrounding buffer zones in 1993, but were lower than in buffer zones in 2009 , indicating low management effectiveness in earlier stages but improved effectiveness later on. In addition, other factors such as traditional ecological knowledge and strict local regulation on guns may also have 
contributed to survival of gibbon populations in some unprotected landscapes before reserves were established, and continued to influence local gibbon survival after reserve establishment (Ma et al. 2019; Zhang et al. 2020).

We found no relationship between reserve administration level (current-day level, level at foundation, and whether reserve had been upgraded) and gibbon survival. A higher level of administration usually means more investment and probably more effective management (Quan et al. 2011). However, our findings suggest that administration level does not reflect management effectiveness for specific gibbon populations. Gibbons have a low reproductive rate, with females breeding every 3-5 years, and are thus very sensitive to poaching (Fan \& Jiang 2007; Phoonjampa \& Brockelman 2008). Although poaching is strictly prohibited across Chinese reserves, it does occur in many reserves in China, including national-level reserves (Gong et al. 2017). For sensitive gibbon populations, any management improvement brought by upgraded administration level can be counteracted by a single poaching event.

\section{The importance of early investment in reserves for species conservation}

Two-thirds of reserves or management areas had been upgraded, with most of them upgraded from provincial-level to national-level, and no area had been downgraded. On average, reserves were upgraded 14 years after establishment, and with most upgrading occurring around 1999. Our findings are in accordance with other studies showing that China has dramatically increased investment in reserves since 2000 (Li et al. 2013). Similarly, reserve staff who participated in our questionnaire survey all reported management effectiveness scores that increased over time (Fig. 2).

\section{Comparisons of Human Footprint Index between reserves and surrounding buffer} zones also indicate an increased general management effectiveness of reserves, a 
pattern also seen in many other PAs around the world (Geldmann et al. 2015).

Nonetheless, this increase in management scores was not associated with positive gibbon population trends over time. This is concerning, as it suggests that increased investment in existing reserves does not automatically increase survival prospects for gibbons. This lack of correlation may be because many reserves were established at a point when gibbon populations were rapidly declining or already on the edge of extinction. However, our results also suggest that reserves established longer ago suffered from limited investment and low management effectiveness. If effective investment during this crucial early time window was missed, subsequent increases in investment appeared to be unable to preserve gibbon populations.

\section{Conservation implications}

We demonstrate that establishment of PAs has not ensured gibbon survival in China. Although it is not possible to determine the critical time window when there was a "best last chance" to save each of these now-extirpated gibbon populations, we argue that immediate investment at early stages (i.e., when PAs were established) is likely to be most helpful for the conservation of such small threatened populations. This is analogous to preventing a traffic accident: conservation practitioners must brake population decline at an early stage, and brake emphatically, to have the best chance of preventing extinction. Nevertheless, delayed investment is better than no investment; conservation efforts have saved many vertebrate species from extinction worldwide (Hoffmann et al. 2010), and even tiny remnant populations can recover, even if they have persisted at very low sizes for several decades (Crees et al. 2016). Indeed, such potential for conservation recovery is shown within our study by the Hainan gibbon, which — although still extremely rare and vulnerable — is showing 
encouraging signs of population recovery (Bryant et al. 2016; Chan et al. 2020).

"Although time is running out, there is still an enormous amount of nature left to fight for" (Balmford 2012).

\section{Supporting Information}

Basic information about reserves (Appendix S1), detailed methods for calculating gibbon population size in the 1980s (Appendix S2), comparison of management effectiveness scores between decades (Appendix S3), and trends of gibbon populations and changes of management scores (Appendix S4), are available online.

The authors are solely responsible for the content and functionality of these materials. Queries (other than absence of the material) should be directed to the corresponding author.

\section{Literature cited}

Balmford A. 2012. Wild Hope: On the Front Lines of Conservation Success. University of Chicago Press, Chicago, USA.

Bartoń K. 2016. MuMIn: Multi-Model Inference.

Brower LP, Castilleja G, Peralta A, Lopez-Garcia J, Bojorquez-Tapia L, Diaz S, Melgarejo D, Missrie M. 2002. Quantitative changes in forest quality in a principal overwintering area of the monarch butterfly in Mexico, 1971-1999. Conservation Biology 16:346-359.

Bryant JV, Brulé A, Wong MHG, Hong X, Zhou Z, Han W, Jeffree TE, Turvey ST. 2016. Detection of a new Hainan gibbon (Nomascus hainanus) group using acoustic call playback. International Journal of Primatology 37:534-547.

Burnham KP, Anderson DR. 2002. Model selection and multimodel inference: a 
400

401

402

403

404

405

406

407

408

409

410

411

412

413

414

415

416

417

418

419

420

421

422

423

424

practical information-theoretic approach, 2nd edition. Springer Verlag, New York, New York, USA.

Chan BPL, Lo YFP, Mo Y. 2020. New hope for the Hainan gibbon: formation of a new group outside its known range. Oryx 54:296-296.

Chapman CA, Corriveau A, Schoof VAM, Twinomugisha D, Valenta K. 2017. Longterm simian research sites: significance for theory and conservation. Journal of Mammalogy 98:652-660.

Chatterjee HJ, Tse JSY, Turvey ST. 2012. Using ecological niche modelling to predict spatial and temporal distribution patterns in Chinese gibbons: lessons from the present and the past. Folia Primatologica 83:85-99.

Claudet J et al. 2008. Marine reserves: size and age do matter. Ecology Letters 11:481-489.

Crees JJ, Collins AC, Stephenson PJ, Meredith HMR, Young RP, Howe C, Stanley Price MR, Turvey ST. 2016. A comparative approach to assess drivers of success in mammalian conservation recovery programs. Conservation Biology 30:694-705.

Curran LM, Trigg SN, McDonald AK, Astiani D, Hardiono YM, Siregar P, Caniage I, Kasischke E. 2004. Lowland forest loss in protected areas of Indonesian Borneo. Science 303:1000-1003.

Dudley N. 2008. Guidelines for Applying Protected Area Management Categories. IUCN, Gland.

Fan P. 2017. The past, present, and future of gibbons in China. Biological Conservation 210:29-39.

Fan P, Ai H, Fei H, Zhang D, Yuan S. 2013. Seasonal variation of diet and time budget of eastern hoolock gibbons (Hoolock leuconedys) living in a northern 
montane forest. Primates 54:137-146.

426

427

428

429

430

431

432

433

434

435

436

437

438

439

440

441

442

443

444

445

446

447

448

449

Fan P, Fei H, Luo A. 2014. Ecological extinction of the Critically Endangered northern white-cheeked gibbon Nomascus leucogenys in China. Oryx 48:5255.

Fan P, Jiang X. 2007. Population viability analysis for black crested gibbon (Nomascus concolor jingdongensis) in Dazhaizi at Mt. Wuliang, Yunnan, China. Acta Ecologica Sinica 27:1-7.

Fan P, Jiang X. 2010. Altitudinal ranging of black-crested gibbons at Mt. Wuliang, Yunnan: effects of food distribution, temperature and human disturbance. Folia Primatologica 81:1-9.

Friedlander AM, Golbuu Y, Ballesteros E, Caselle JE, Gouezo M, Olsudong D, Sala E. 2017. Size, age, and habitat determine effectiveness of Palau's Marine Protected Areas. PLoS One 12:e174787.

Geldmann J et al. 2015. Changes in protected area management effectiveness over time: a global analysis. Biological Conservation 191:692-699.

Geldmann J et al. 2018. A global analysis of management capacity and ecological outcomes in terrestrial protected areas. Conservation Letters 11:e12434.

Geldmann J, Barnes M, Coad L, Craigie ID, Hockings M, Burgess ND. 2013. Effectiveness of terrestrial protected areas in reducing habitat loss and population declines. Biological Conservation 161:230-238.

Gong S, Shi H, Jiang A, Fong JJ, Gaillard D, Wang J. 2017. Disappearance of endangered turtles within China's nature reserves. Current Biology 27:R170R171.

Grueter CC, Jiang X, Konrad R, Fan P, Guan Z, Geissmann T. 2009. Are Hylobates lar extirpated from China? International journal of primatology 30:553-567. 
450 451

452

Han N. 2000. A policy study on sustainable management for China's nature reserves. Journal of Natural Resources 15:201-207.

Hijmans RJ. 2020. raster: Geographic Data Analysis and Modeling.

Hoffmann M et al. 2010. The impact of conservation on the status of the world's vertebrates. Science 330:1503-1509.

Hu Y, Luo Z, Chapman CA, Pimm SL, Turvey ST, Lawes MJ, Peres CA, Lee TM, Fan P. 2019. Regional scientific research benefits threatened-species conservation. National Science Review 6:1076-1079.

Jenkins CN, Joppa L. 2009. Expansion of the global terrestrial protected area system. Biological Conservation 142:2166-2174. Elsevier.

Kang D, Li J. 2018. Role of nature reserves in giant panda protection. Environmental Science and Pollution Research 25:4474-4478.

Laurance WF et al. 2012. Averting biodiversity collapse in tropical forest protected areas. Nature 489:290-294.

Legendre S, Clobert J, Møller AP, Sorci G. 1999. Demographic stochasticity and social mating system in the process of extinction of small populations: the case of passerines introduced to New Zealand. The American Naturalist 153:449463.

Li BV. 2020. Conservation: guarding panda land. Current Biology 30:R302-R304.

Li BV, Pimm SL, Li S, Zhao L, Luo C. 2017. Free-ranging livestock threaten the long-term survival of giant pandas. Biological Conservation 216:18-25.

Li J et al. 2014. Role of Tibetan Buddhist monasteries in snow leopard conservation. Conservation biology 28:87-94.

Li Y, Li W, Zhang C, Fan M. 2013. Current status and recent trends in financing China's nature reserves. Biological Conservation 158:296-300. 
Liu J, Linderman M, Ouyang Z, An L, Yang J, Zhang H. 2001. Ecological degradation in protected areas: the case of Wolong Nature Reserve for giant pandas. Science 292:98-101.

Liu J, Viña A, Yang W, Li S, Xu W, Zheng H. 2018. China's environment on a metacoupled planet. Annual Review of Environment and Resources 43:1-34.

Liu Z, Zhang Y, Jiang H, Southwick C. 1989. Population structure of Hylobates concolor in Bawanglin Nature Reserve, Hainan, China. American Journal of Primatology 19:247-254.

Ma C, Trinh-Dinh H, Nguyen V-T, Le T-D, Le V-D, Le H-O, Yang J, Zhang Z, Fan P. 2019. Transboundary conservation of the last remaining population of the cao vit gibbon Nomascus nasutus. Oryx:In press.

Margules CR, Pressey RL. 2000. Systematic conservation planning. Nature 405:243253.

Naimi B, Hamm NAS, Groen TA, Skidmore AK, Toxopeus AG. 2014. Where is positional uncertainty a problem for species distribution modelling? Ecography 37:191-203.

O’Neil ST, Coates PS, Brussee BE, Ricca MA, Espinosa SP, Gardner SC, Delehanty DJ. 2020. Wildfire and the ecological niche: diminishing habitat suitability for an indicator species within semi-arid ecosystems. Global Change Biology:In press.

Ouyang $Z$ et al. 2016. Improvements in ecosystem services from investments in natural capital. Science 352:1455-1459. American Association for the Advancement of Science.

Ouyang Z, Xu W, Du A. 2018. Research on Overall Spatial Planning for China's National Park System. China Environment Press Corp, Beijing. 
Pearce J, Ferrier S. 2000. Evaluating the predictive performance of habitat models developed using logistic regression. Ecological Modelling 133:225-245.

Phoonjampa R, Brockelman WY. 2008. Survey of pileated gibbon Hylobates pileatus in Thailand: populations threatened by hunting and habitat degradation. Oryx 42:600-606.

Phoonjampa R, Koenig A, Brockelman WY, Borries C, Gale GA, Carroll JP, Savini T. 2011. Pileated gibbon density in relation to habitat characteristics and postlogging forest recovery. Biotropica 43:619-627.

Piel AK, Lenoel A, Johnson C, Stewart FA. 2015. Deterring poaching in western Tanzania: the presence of wildlife researchers. Global Ecology and Conservation 3:188-199.

Pohlert T. 2014. The Pairwise Multiple Comparison of Mean Ranks Package (PMCMR).

Pusey AE, Pintea L, Wilson ML, Kamenya S, Goodall J. 2007. The contribution of long-term research at Gombe National Park to chimpanzee conservation. Conservation Biology 21:623-634.

Quan J, Ouyang Z, Xu W, Miao H. 2011. Assessment of the effectiveness of nature reserve management in China. Biodiversity and Conservation 20:779-792.

R Core Team. 2016. R: a language and environment for statistical computing. R: foundation for Statistical Computing, Vienna, Austria.

Ren G, Young SS, Wang L, Wang W, Long Y, Wu R, Li J, Zhu J, Yu DW. 2015. Effectiveness of China's National Forest Protection Program and nature reserves. Conservation Biology 29:1368-1377.

Riley SJ, DeGloria SD, Elliot R. 1999. A terrain ruggedness index that quantifies topographic heterogeneity. Intermountain Journal of Sciences 5:23-27. 
Saccheri I, Kuussaari M, Kankare M, Vikman P, Fortelius W, Hanski I. 1998. Inbreeding and extinction in a butterfly metapopulation. Nature 392:491-494. Nature Publishing Group.

Sing T, Sander O, Beerenwinkel N, Lengauer T. 2005. ROCR: visualizing classifier performance in R. Bioinformatics 21:3940-3941.

Swaisgood RR, Wang D, Wei F. 2018. Panda downlisted but not out of the woods. Conservation Letters 11:1-9.

Turvey ST et al. 2017. How many remnant gibbon populations are left on Hainan? Testing the use of local ecological knowledge to detect cryptic threatened primates. American Journal of Primatology 79:e22593.

Turvey ST, Bruun K, Ortiz A, Hansford J, Hu S, Ding Y, Zhang T, Chatterjee HJ. 2018. New genus of extinct Holocene gibbon associated with humans in Imperial China. Science 360:1346-1349.

Turvey ST, Crees JJ, Di Fonzo MMI. 2015. Historical data as a baseline for conservation: reconstructing long-term faunal extinction dynamics in Late Imperial-modern China. Proceedings of the Royal Society B: Biological Sciences 282:20151299.

Watson JEM, Dudley N, Segan D, Hockings M. 2014. The performance and potential of protected areas. Nature 515:67-73.

Wei $\mathrm{F}$ et al. 2018. The value of ecosystem service from giant panda reserves. Current Biology 28:2174-2180.e7.

Wei F, Hu Y, Zhu L, Bruford MW, Zhan X, Zhang L. 2012. Black and white and read all over: the past, present and future of giant panda genetics. Molecular Ecology 21:5660-5674.

Wei W et al. 2020. Assessing the effectiveness of China's panda protection system. 

Current Biology 30:1280-1286.e2.

551 Wickham H. 2016. ggplot2: Elegant Graphics for Data Analysis. Springer-Verlag, 552 New York.

553

554

555

556

557

Xu H, Wang S, Xue D. 1999. Biodiversity conservation in China: legislation, plans and measures. Biodiversity and Conservation 8:819-837.

Xu W, Pimm SL, Du A, Su Y, Fan X, An L, Liu J, Ouyang Z. 2019. Transforming protected area management in China. Trends in Ecology \& Evolution 34:762766.

Yuan S, Fei H, Zhu S, Cui L, Ai H, Fan P. 2014. Effects of tsaoko (Fructus tsaoko) cultivating on tree diversity and canopy structure in the habitats of eastern hoolock gibbon (Hoolock leuconedys). Zoological Research 35:231-239.

Zhang L, Guan Z, Fei H, Yan L, Turvey ST, Fan P. 2020. Influence of traditional ecological knowledge on conservation of the skywalker hoolock gibbon (Hoolock tianxing) outside nature reserves. Biological Conservation 241:108267.

Zhang M, Fellowes JR, Jiang X, Wang W, Chan BPL, Ren G, Zhu J. 2010. Degradation of tropical forest in Hainan, China, 1991-2008: conservation implications for Hainan gibbon (Nomascus hainanus). Biological Conservation 143:1397-1404.

Zhou J, Wei F, Li M, Zhang J, Wang D, Pan R. 2005. Hainan black-crested gibbon is headed for extinction. International Journal of Primatology 26:453-465.

571 


\section{Tables}

574 Table 1. Independent variables included in logistic regression models investigating characteristics of nature reserves that were associated with

575 gibbon persistence into the 2010s.

\begin{tabular}{lllll}
\hline Variable & Description & Prediction & Reference & Data source / resolution \\
\hline LEV & Administration level: a) & Higher-level reserves have stricter & (Dudley 2008) & Reserve websites / NA \\
& national; b) provincial; c) & regulations, so provide greater & & Reserve websites / NA \\
& county-level & protection to gibbon populations & & (Claudet et al. 2008; \\
AGE & Age of reserve (years) & Reserve age is positively correlated & Phoonjampa et al. & 2011) \\
& & with gibbon population survival & SRM v4 / 90 m \\
ELE & Mean elevation of reserve & Higher elevation has negative impact & (Fan \& Jiang 2010) &
\end{tabular}


TRI Mean topographic ruggedness More rugged terrain is beneficial to index within reserve

TEM Mean annual temperature $\left({ }^{\circ} \mathrm{C}\right)$

FOR Forest cover in year 2000

PFL Percentage forest loss during 2000-2018

HFI Percentage HFI change during 1993-2009

PAP Number of papers published in both Chinese and English referring to reserve and its

gibbon population gibbon survival

Lower temperature has negative impact on gibbon populations

Higher forest cover provides better habitat for gibbons

Forest loss has negative impact on gibbon populations

Human disturbance has negative impact on gibbon populations

Scientific research benefits threatened species conservation

POP Size of gibbon populations in Small populations are more likely to

(Li et al. 2014; O’Neil Calculated from SRTM DEM

(Fan \& Jiang 2010)

et al. 2020)

(Fan et al. 2013)

(Phoonjampa et al.

(Phoonjampa et al.

\section{(Hu et al. 2019)}

$x^{2}$ $\mathrm{v} 4 / 90 \mathrm{~m}$

WorldClim / 30 arc-seconds

Global Forest Change 2000$2018 / 30 m$

Global Forest Change 20002018 / $30 \mathrm{~m}$

NASA Socioeconomic Data and Applications Center / 1 km

China National Knowledge

Infrastructure, Web of Science

/ NA

(Saccheri et al. 1998) Published literature and first- 
the 1980 s

become extinct

hand data

576 "Including 3 variables: current administration level, level at reserve establishment, and whether reserve had been upgraded. 
578 Table 2. Logistic regression models, ranked by their AICc, explaining

579 presence/absence of gibbons in 18 reserves or management areas after 2010 based on 58010 independent variables. Loglik, log-likelihood; $\triangle \mathrm{AICc}$, difference in AICc values 581 between each model and the best model; $\omega_{i}$, Akaike weight.

\begin{tabular}{lllll}
\hline Variables & LogLik & AICc & $\Delta$ AIC & $\omega_{i}$ \\
\hline Elevation & -9.37 & 23.535 & 0.000 & 0.228 \\
Reserve age & -9.38 & 23.555 & 0.019 & 0.226 \\
Papers & -9.45 & 23.707 & 0.171 & 0.210 \\
Percentage forest loss & -9.93 & 24.660 & 1.125 & 0.130 \\
Gibbon population size in 1980s & -10.32 & 25.448 & 1.913 & 0.088 \\
Percentage HFI change & -10.71 & 26.213 & 2.678 & 0.060 \\
Forest cover in 2000 & -10.98 & 26.750 & 3.215 & 0.046 \\
Administration level at founded & -11.75 & 28.308 & 4.773 & 0.020 \\
Whether reserve had been & & & & \\
upgraded & -12.14 & 29.074 & 5.538 & 0.014 \\
Current-day administration level & -12.34 & 29.475 & 5.940 & 0.011 \\
\hline
\end{tabular}

583 Table 3. Model-averaged coefficients and relative importance of variables for logistic 584 regression models analyzing variables associated with presence/absence of gibbons in 58518 reserves or management areas after 2010.

\begin{tabular}{llll}
\hline Variables & Coefficien & Relative importance \\
& $\mathrm{t}$ & $\mathrm{SE}$ & based on $\omega_{i}$ \\
\hline (Intercept) & 0.312 & 2.881 & \\
Elevation & 0.002 & 0.001 & 0.242
\end{tabular}




$\begin{array}{llcc}\text { Reserve age } & -0.113 & 0.062 & 0.240 \\ \text { Papers } & 0.370 & 0.304 & 0.223 \\ \text { Percentage forest loss } & -0.941 & 0.588 & 0.138 \\ \text { Gibbon population size in 1980s } & 0.018 & 0.012 & 0.093 \\ \text { Percentage HFI change } & -9.968 & 6.111 & 0.064\end{array}$

586

587

$588 \quad$ Figures

589 Figure 1. Comparison of forest cover in 2000, percentage forest loss in 2000-2018,

590 and human footprint indices in 1993 and 2009, between reserves and their $5 \mathrm{~km}$ buffer

591 zones. $* * *$ difference significant at $P<0.001$. N.S. difference not significant.

592

593 Figure 2. Comparison of mean scores of all questions (All) and of 4 question

594 groupings (G1: Design and Planning, G2: Monitoring and Enforcement, G3: Capacity

595 and Resources, G4: Decision-making Arrangement) across decades. Different

596 lowercase letters indicate significant differences at $P<0.05$.

597

598 

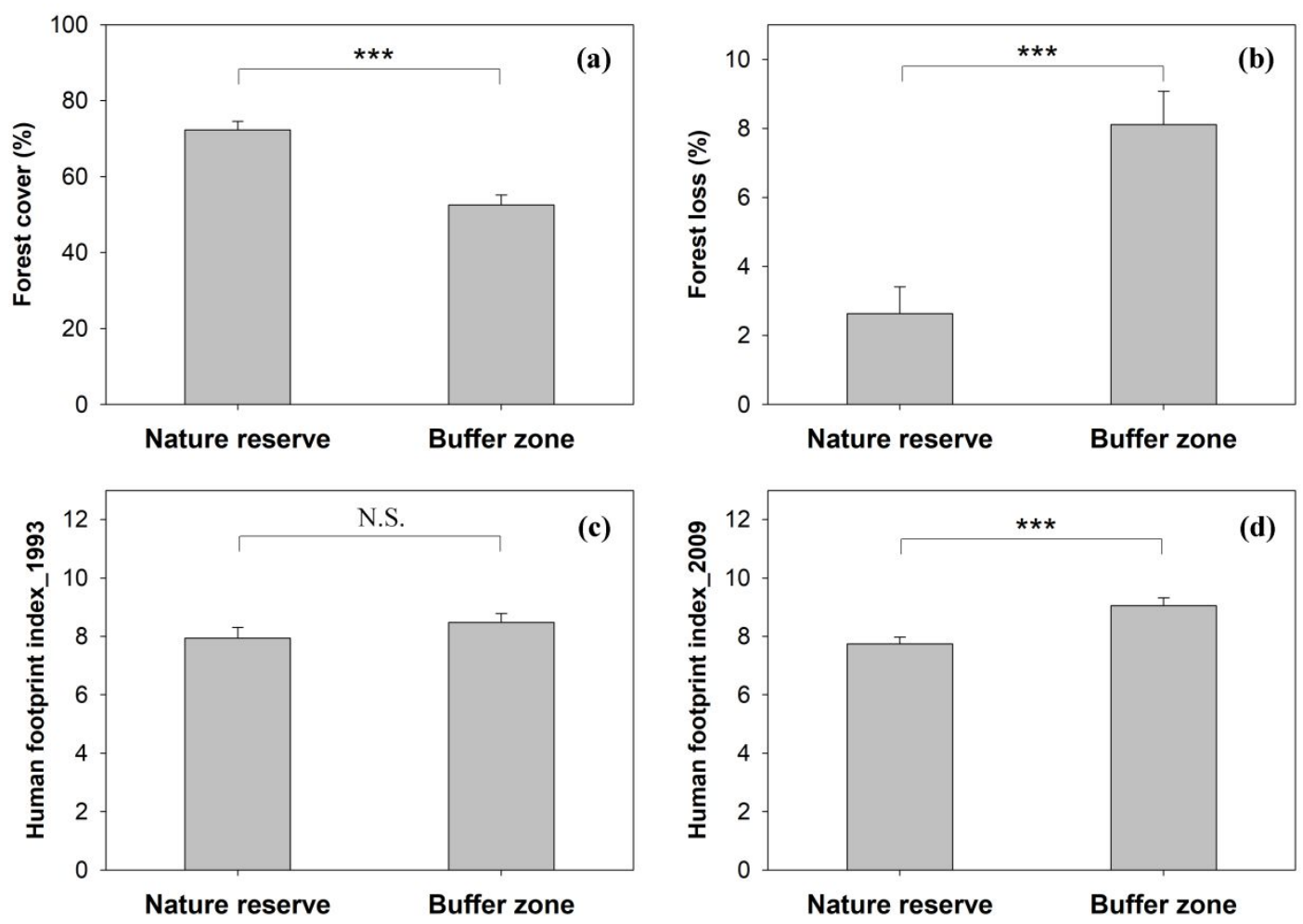

599

600

Figure 1.

601

602
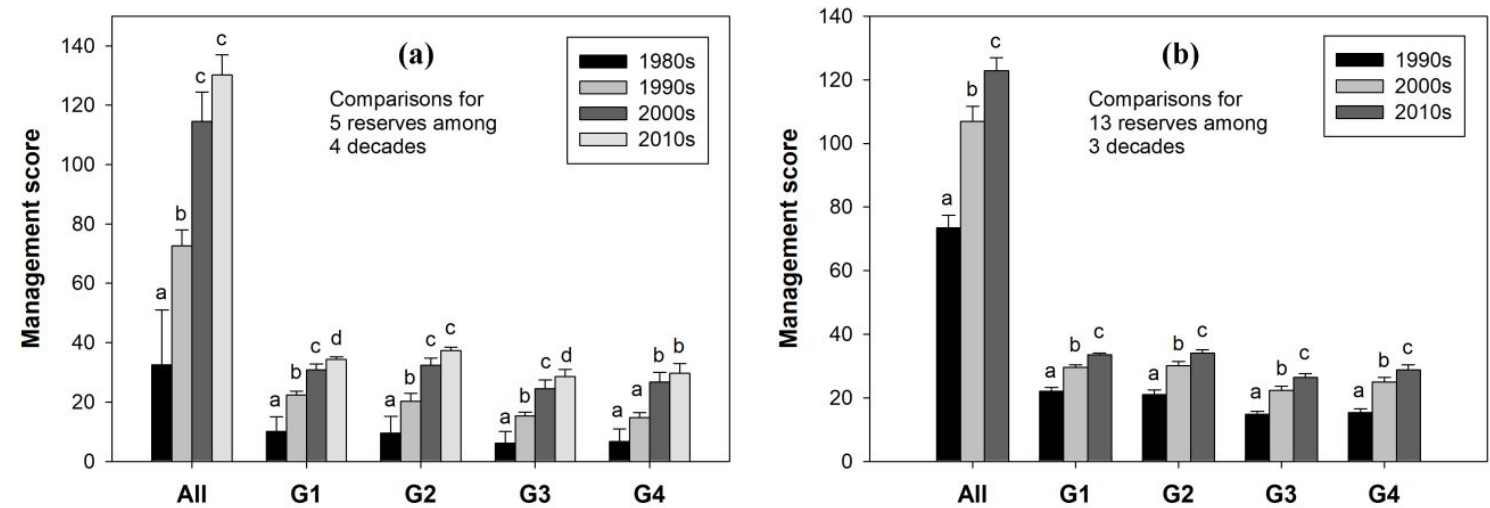

603 Figure 2. 